\title{
LA NARRATIVA EGIPCIA
}

\author{
Eugenia Gálvez
}

Hablar de narrativa egipcia es hablar de renacimiento, es decir, de nahda, que tal es la expresión árabe que lo define. Y ello lleva consigo, en primer lugar, hacer un breve resumen histórico para poderse centrar dentro del mismo, ya que la historia juega un papel importante en el nacimiento de la narrativa egipcia. Nos proponemos también unos límites de espacio y de tiempo dentro de los cuales nos moveremos con el fin de concretar lo extenso del tema. Hechos históricos que abarcarán desde 1798, fecha de la Expedición a Egipto hasta finales de los años cincuenta cuando dicho país encuentra en cierto modo su identidad. También pondremos un límite a los autores y obras que se produjeron en este espacio temporal, pues lo contrario nos obligaría a hacer una mera enumeración de unos y otros por ser ésta una etapa muy fructífera en lo que a producción literaria se refiere. Nos fijaremos, por tanto, con más detenimiento en Mạ̣mūd Taymūr (1894-1973), Ṭaha Husayn (1889-1973), Tawfĩq al-Hakīm (1898-1987) y Naŷỉb Maḥuũ (1912- ), como los autores más significativos de este género.

\section{Etapas históricas.}

Fijaremos la primera en el tiempo comprendido entre 1798 y 1882. Dos personas básicas: Napoleón Bonaparte y Muhammad 'Alī. El primero suscita con su expedición a Egipto la vuelta de Europa hacia Oriente desde el punto de vista cultural, pero al mismo tiempo Oriente despierta y vuelve su mirada a Europa y, lo que es más importante, intenta una puesta al día. Muḥammad 'Alī será el propulsor de esa puesta al día, de ese despertar.

Egipto es, politicamente hablando, provincia otomana, pero tras la expedición napoleónica y tras cuatro años de guerras civiles Muḥammad 'Alī conseguirá ponerse a la cabeza del poder logrando el monopolio del Estado generalizado: agricultura, industria y comercio. Este déspota ilustrado - valga la expresiónserá el gran renovador de Egipto. Creará una dinastía que tendrá vigencia hasta 
1952 y en la que destacará su nieto Ismā'îl vinculado a la apertura del Canal de Suez y bajo cuyo reinado se decreta la lengua árabe como lengua oficial de la administración.

La segunda etapa ha de ser fijada en el momento en que Egipto pasa al dominio británico, sin dejar por ello de ser provincia del Imperio otomano, pero sin dependencia real de la Sublime Puerta. Tras la intervención del héroe nacional 'Urabī y bajo el reinado de Tawfĩq, las escuadras francesa e inglesa entran en Alejandría siendo esta ciudad bombardeada por los ingleses que quedan dueños de la situación y que, tras la retirada de los franceses, ocupan el país. La ocupación británica terminará en 1914, al dejar Egipto de ser provincia otomana y convertirse en Protectorado Británico.

La tercera etapa se puede iniciar en el año 1922 cuando, tras los graves acontecimientos de 1919 — que tanto influirán en la temática de los narradores egipcios - el país obtiene una independencia nominal con la promulgación de una Constitución al año siguiente, y con el nombre de Reino de Egipto, siempre bajo la vigilancia de la Gran Bretaña, por medio de un Alto Comisario que promueve una vuelta forzada de las tropas durante el período de entreguerras.

El final de la Segunda Guerra Mundial provoca en Egipto paro y subempleo pues los obreros son despedidos de su trabajo por los ingleses. Las huelgas se multiplican y las manifestaciones tanto sociales como políticas se suceden bajo el signo del sentimiento anti británico. Todo ello desembocará en la última etapa objeto de nuestro estudio que queda marcada por la fecha de 1953, llamada también «de los oficiales». Egipto, convertido en República, ha ordenado previamente la evacuación de los británicos. La monarquía es abolida el 18 de junio de 1953 y toma el mando el general Naguib al lado del cual se irá perfilando la personalidad del oficial Gamal Abdel Naser que el 23 de junio de 1956 es elegido Presidente de la República. Este régimen alejó del poder a las antiguas clases dirigentes siendo sustituídas por otros grupos sociales en un intento de reforma socialista sui generis que se fue inclinando progresivamente hacia la dictadura militar. Todos estos momentos históricos van modelando el sentimiento de nacionalismo y el modo de ser y de pensar del pueblo egipcio dando lugar a nuevos conceptos básicos en la formación de su pensamiento ${ }^{1}$.

El nacionalismo, el laicismo y el faraonismo son las tres nuevas líneas que apunta el escritor Muhammad Haykal en 1919. Egipto tiene necesidad de su identificación como nación - umma - con derecho a actuar libremente ante su presente y su futuro. El concepto laico de la nación inexistente hasta entonces y la vuelta hacia un pasado glorioso que no fuera necesariamente el islámico, sino otro tan digno de recordar como éste, pero más lejano: el faraonismo. Junto a esta líneas claves para Haykal y para otros muchos existen hechos sociales indiscutibles. Uno de los más importantes es el nacimiento de una clase liberal laica de origen netamente egipcio por una parte. El nacimiento y afianzamiento de la Prensa, factor de vital importancia, pues a través de ella se va a librar la batalla por la adaptación de los géneros literarios occidentales, por otra. Esto dará lugar a

1 N. Tomiche, L'Egypte moderne (Paris: Presses universitaires de France, 1966) p. 8. 
la creación de la llamada al-Madrasa al-Hadita (La Nueva Escuela) agrupada en torno a la revista al-Sufür y que contará con nombres como los de los hermanos Taymūr, los hermanos Lašin, etc. Personas pertenecientes a la alta burguesía y a la aristocracia no egipcia, pero dedicadas desde el siglo XIX al estudio de la lengua árabe y a las letras en general como la familia Taymūr. Por lo general no están inmersos en la lucha político-social y casi todos se estancan en la narrativa breve, con grandes excepciones como es el caso de Maḥmūd Taymūr o de Tāhir Lašin.

Al-Siyāsa es otra publicación periódica a cargo del escritor Muhammad $\mathrm{Hu}$ sayn Haykal del que ya hemos hablado. Es el órgano del Partido Liberal Constitucional y vinculado a la generación llamada del 89 (T⿳亠一冖巾 Tawfïq al-Hakīm y otros). Son los representantes de la clase social que protagoniza el movimiento nacionalista, generalmente de extracción campesina, excepto, por ejemplo, Tawfīq al-Hakīm, nacido en Alejandría y perteneciente a la clase media. El reconocimiento de la realidad occidental y el amor a su propio país creará en ellos un sentimiento de fracaso y de derrota ${ }^{2}$.

\section{Orígenes.}

Si buscamos los orígenes de la narrativa egipcia hemos de remontarnos a la fecha de 1882 donde, tras la ocupación inglesa emerge una joven generación de autores que no tiene miedo a criticar a su sociedad tanto desde el punto de vista socio-político como desde el socio-cultural. Se cuentan entre ellos Muhammad 'Abduh, Qāsim Amīn y Fath Zaglūl. También a finales del siglo XIX tendrá lugar una nueva orientación religiosa representada por una nueva interpretación del Corán, a cargo de Muhammad 'Abduh, por medio de una serie de comentarios publicados en el periódico al-Manār. En 1898 aparece en el diario Al-mișbāh alsarq, la publicación por entregas de la novela de Muhammad al-Muwaylihī Hadît 'Is $\bar{a} b$. Hišàm (El relato de 'Isā b. Hišām), diario del que el padre del autor era dueño. Esta puede ser la primera obra narrativa en la que se encuentran ciertos antecedentes de lo que más adelante vaya a ser la narrativa egipcia ${ }^{3}$.

El cuento nace en la calle, es urbano. Es como el espejo de una pequeña burguesía agobiada por las necesidades de la vida y sus aspiraciones contradictorias. Más adelante el tema rural será abarcado de manera naturalista y realista por diversos autores. Hacia los años veinte aparecen los primeros relatos de los hermanos Lašin y de Muhammad y Mạ̣mūd Taymūr. Al mismo tiempo tenemos la novela de al-Māzinī y sobre todo a Țāhā Husayn y a Tawfīq al-Hakīm.

Lo mismo que en Occidente, la novela se extiende en Egipto bajo la égida de una burguesía ascendente. Este género literario no debe su pasado a la lengua

2 M. del Amo, «Aproximación a la novela egipcia de entreguerras» Miscelánea de estudios árabes y hebráicos, p. 16-17.

3 Ali ben Jad, Form and Technique in the Egyptian Novel, 1912-1971 (Oxford: Ithaca Press, 1983) p. 1 . 
árabe; tanto el cuento como la novela egipcios deben su nacimiento a la literatura occidental, abarcando a franceses, ingleses, rusos y norteamericanos. Por tanto la tradición de este género hay que buscarla en Occidente y no en la tradición nacional. No se trata de una imitación ni de una moda pasajera sino que sirve de estímulo y condicionamiento sicológico facilitando la empresa del escritor sobre el universo que le rodea. El genio de la lengua, los imperativos del argumento y su ajustamiento a la realidad hacen que, a pesar de las influencias occidentales, los autores árabes sean totalmente originales. Los periódicos y revistas, como ya hemos visto, son el primer vehículo para la difusión de los géneros en cuyas páginas se publican traducciones de cuentos y novelas occidentales para más adelante transformarse estos mismos traductores en autores, dando comienzo a la publicación de folletones originales que al principio son producciones tímidas y marginales. El género novelístico era considerado a principios del siglo XX, como peligroso para las costumbres e indigno de la expresión literaria. La fuerza e influencia de los ulemas es un obstáculo para la publicación de cualquier obra de este género, pero en 1914 aparece la que ya podemos llamar primera novela egipcia, Zaynab, de Muhammad Husayn Haykal (1888-1956), novela de tinte romántico, con fines moralistas y la narración de amores platónicos y contrariados tan del gusto de la sociedad a la que va dirigida. A partir de este momento el campo egipcio con sus problemas y su miseria será uno de los temas más tocados por los escritores egipcios, pero casi siempre de modo idealista. Este concepto variará con la aparición de la novela al-Ard (La tierra) de Sarqawī donde se plantean conceptos de denuncia y reivindicación. Esta novela aparece en 1954.

La aparición de la novela se presenta como una incidencia del pensamiento occidental sobre la élite de un país dominado por una burguesía agrícola agitada por las corrientes contrarias del conservadurismo y del modernismo ${ }^{4}$. El progreso de la enseñanza que esa élite ha creado le proporciona también un público y el desarrollo de la prensa los medios para conseguirlo. Pero es la liberación de las costumbres, la disminución del autoritarismo patriarcal y la cerrazón de las clases sociales lo que da carta de soberanía a la literatura de ficción que es hija de los nuevos tiempos sin raíz alguna de tradición. A partir de la nahda y a lo largo de los años que van desde el final del siglo XIX hasta la Segunda Guerra Mundial los escritores árabes forjan una literatura en armonía con los nuevos tiempos. Esta evolución no se detendrá y, tras la Segunda Guerra se asiste a una gran producción literaria. Los escritores egipcios se dejan también arrastrar por esa fascinación bebiendo en los modelos occidentales pero sin dejar atrás su mundo hasta tal punto sometidos al mismo, que cuando Muhammad Husayn Haykal, conocido político, publica su novela Zaynab lo hace bajo seudónimo.

Hay que decir también que este grupo de escritores en sus comienzos y casi en su mayoría se inclinaron por el cuento como es el caso de Maḥmūd Taymūr, Naŷî̉ Maḥfūz o Yūsuf al-Sibā'ī, pero la mayoría de ellos pasa después con ma-

4 R. y L. Makarius, Anthologie de la Littérature Arabe Contemporaine, I, Le roman et la nouvelle (Paris: Editions du Seuil) p. 19. 
yor o menor fortuna a la novela. También podemos considerar lo que Maḥmūd Taymūr denomina riwāyya qișașiyya cuya traducción podría ser novela corta, como es el caso de Yahyā Haqqī en el Qindīl Umm Hašìm (El candil de Umm Hašìm).

Aunque todos los precursores en estos estilos forjaron su obra como consecuencia de una toma de conciencia nacional, los autores de la postguerra, hijos de una burguesía pobre sumergida en el seno de las masas populares, escriben tras una toma de conciencia social y estos autores comprometidos reprochan a los anteriores de falta de la misma. Lo que diferencia a los naturalistas de los años veinte a treinta de los realistas de los cincuenta es la carga de sufrimiento y revuelta contenida en sus obras; pero esto no es del todo cierto porque tras la dulce exposición de los hechos de un Ṭāhā Husayn en Kitāb al-ayyām (Los días) y un Sarqawī agresivo en al-Ard (La tierra) hay el mismo grito de dolor expresado de distinta manera. O la crítica burlona que hace del campo Tawfīq al-Hakīm en Yawmiyyāt $n \bar{a}$ 'ib fi-l-arya $\bar{f}$ (Diario de un fiscal rural) tras la que se oculta un indecible desencanto y una terrible amargura.

Como resumen de todo lo expuesto podemos sistematizar las tendencias ideológicas y temáticas del siguiente modo:

- Grupo de la Nueva Escuela y grupo del 89. Gran fe en el carácter egipcio para formar un nuevo futuro consecuencia de la Constitución de 1923 tras las revueltas de 1919 (Taymūr, Lašinn).

- Etapa de entreguerras. El dilema, el dolor, la desilusión tras los cantos de independencia de 1936. (Mahmūu Taymūr, Ṭāhā Husayn, Tawfīq al-Hakīm).

- Tras la Segunda Guerra Mundial. Una nueva generación con las siguientes características y tendencias:

a) Tendencia sentimental y melodramática. Escapismo (Yūsuf alSibā' $\overline{1}^{1}$.

b) Tendencia romántica con aspiraciones de conseguir un presente mejor (Ibrāhīm al-Mașrī).

c) Tendencia realista (Yahyā Haqqī, Naŷî̉ Maḥfüz, Sarqawīi) ${ }^{5}$.

Factor indispensable para la realización de todo lo que venimos afirmando es la lengua. ¿Qué ha pasado con la lengua árabe? Existe por una parte la riqueza lexicográfica o la abundancia de sus clichés. Las formas verbales se diversifican a partir de una raíz fija. Pero el verbo es pobre en formas que expresen la temporalidad diferenciada y por otra parte el empleo de los pronombres llevan al prosista a una ausencia fatal de claridad y precisión. Su sintaxis simplista se acomoda mal al período que supone una gran ligereza en las subordinadas. Para crear una literatura nueva la lengua árabe, desposeída tras la dominación turca de su rasgo de lengua de civilización, solamente subsistía en los campos a modo de jerga indígena. Costaría trabajo hacerla desempeñar de nuevo el papel de lengua de unión entre los musulmanes a no ser que se operara una revolución profunda en su léxico. Había que renunciar al lenguaje exuberante que era bueno para expresarse en poesía y, por el contrario, crear nuevas palabras para expresar realidades

5 M. del Amo, «Aproximación a la novela egipcia de entreguerras». Miscelánea de estudios árabes y hebráicos, $p$. 23-35. 
materiales, intelectuales o morales desconocidas u olvidadas por los árabes. Este trabajo requerirá conocimientos filológicos muy vastos y es por lo que los escritores de la nueva época se aferran al estudio de la lengua para depurarla y enriquecerla a la vez. Maḥmūd Taymūr, Ṭāhā Husayn y Tawfīq al-Hakīm lo demuestran entre otros con sus estudios y ensayos expresando sus dudas, sus tanteos, su evolución y su adaptación a los nuevos tiempos a lo largo de toda su obra literaria. El gusto por los clásicos se desarrollará a lo largo de 1882 a 1918; pero esta vez la influencia de las literaturas europeas se afirma con fuerza: el esfuerzo para aclimatar géneros desconocidos de la literatura clásica es muy duro porque el público no los comprende al principio y se une a tal dificultad la que oponen los elementos conservadores religiosos y el índice de analfabetismo que en 1917 era del $91,3 \%{ }^{6}$. Es para la lengua un período de dudas tremendas, un conflicto entre lo clásico y lo moderno, lo sujetivo y lo objetivo. Las palabras nuevas aparecen como consecuencia de las situaciones reales. Palabras como qawmiyya (nacionalismo) o umma (nación), pero también wuŷūdiyya (existencialismo) o hirmān (frustración). La innovación lingüística podría calificarse de iconoclasta. Hay una especie de puja con el dialecto que a veces llena de perplejidad a los propios autores. La modernización requiere la renuncia de ciertos valores léxicos y cada uno responde a ello según su talento personal.

En cuanto a la temática la fuente de inspiración es siempre el pueblo egipcio ya sea urbano o campesino. Pero en el segundo caso creemos que casi todos los autores desde la primera época hasta bien entrado el período de entreguerras son presa de una fascinación poética por el campo. Aunque algunos de ellos han nacido campesinos, éstos se ven redimidos por su educación intelectual sintiéndose afectados de una manera especial por los problemas urbanos ante los cuales reaccionan con violenta sinceridad, a veces brutal, mientras que en los temas rurales uno cree percibir casi siempre una evocación en cierto modo nostálgica o condescendiente. Los personajes, el escenario, todo es igual, pero a partir de los años treinta empieza a haber más fluidez, todo parece estar menos encorsetado. Se introduce el concepto de suicidio — bastante ajeno a la mentalidad egipcia - y el de la prostitución sin redención: Bidāya wa nihāya (Principio y fin), temas que hacen recaer la censura sobre las obras.

Entre los aspectos de la vida egipcia más tocados por todos los autores de esta época encontramos la actitud de los jóvenes ante los acontecimientos del año 1919, reflejados en $A$ wdat al-rūh (El despertar de un pueblo) de Tawfīq al-Hakīm, o la Tulātiyya (Trilogía) de Naŷì Maḥfūz.

En lo autobiográfico tenemos $A$ wdat al-rūh arriba mencionada, que relata los años de estudiante del autor en El Cairo, y Usfür min al-šrarq (Pájaros de Oriente) de Tawfīq al-Hakīm que relata las experiencias del autor durante su estancia en Francia. El tema autobiográfico abunda en la generación del noventa y ocho y posiblemente la obra más representativa es, junto con las ya citadas Kitāb alayyām (Los días) de Ṭāhā Husayn.

6 R. y L. Makarius, Anthologie de la Littérature Arabe Contemporaine. I. Le roman et la nouvelle (Paris: Editions du Seuil, 1964) p. 24. 
En la opción por Oriente y Occidente citaremos Quindī Umm Hašìm de Yạ̣yā Haqqī y la obra de Tawfīq al-Hakīm ya citada Usfür min al-šrarq. Tendremos que esperar la producción de Naŷîb Maḥfūz para, con su magistral arte, dar la medida de estos personajes, podamos hablar de la mujer. Los autores anteriores se ocupan de ella, pero hay que reconocer que Muhammad Husayn Haykal reacciona en idealista ante el elemento femenino, Mahmūud Taymūr es vago y Tawfīq al-Hakīm no se define. El tema rural lo hemos analizado más arriba. Yawmiyyāt $n \bar{a}$ 'ib fi al-aryāf supondrá la iniciación del realismo en el mismo que culminará con al-Ard de Sarqawī.

Analizaremos a continuación los autores que nos proponíamos y lo más destacado de sus obras. Aunque en principio puede parecer sencillo elegir autor y obra significativos de una època o de una tendencia, es muy difícil no caer en la sujetividad, aunque por otra parte algunos de los autores del período de tiempo que nos ocupa han adquirido dimensiones tan colosales que no resulta extraño ser coincidente en estos personajes destacados ya de manera unánime.

Corresponde el primer lugar por orden cronológico a Mahmmūr Taymūr cuya extensa obra abarca casi todos los nuevos géneros, el cuento, la novela, el teatro y el ensayo. Pero su nombre ha pasado con letras mayúsculas a la historia de la literatura egipcia como el más eximio representante de la narración breve o del cuento, al-qișsa. No podemos dejar pasar por alto la influencia que su hermano Muhammad, dos años mayor que él, ejerció sobre el autor con su obra condensada toda ella en una única colección de cuentos, Mā tarāhu al-'uyūn (Lo que ven los ojos) recogidos por el propio Mạ̣mūd tras la muerte de aquél acaecida en 1921. Esta muerte prematura fue la que le decidió a convertirse él mismo en escritor y presentarnos, a través de sus numerosos cuentos una serie de personajes egipcios de una riqueza y variedad poco comunes. Su primera colección publicada en 1925 el $A l$-šayj $\hat{Y} u m$ 'a wa-aqāșiș ujră' (El šayj Ŷum'a y otros cuentos). En su prólogo expone su propio concepto sobre el cuento árabe, gẹ́nero que, según él, fue cultivado en Egipto por vez primera por su hermano Muhammad. Resalta la necesidad de apoyo que tiene la nueva narrativa árabe porque es, dentro de la selva de la literatura, como un débil brote que hay que cuidar para que no perezca ahogado por los demás árboles. Se muestra defensor de la escuela realista (wāqi $\left.{ }^{\dagger} \vec{l}\right)$ a pesar de que dicha escuela fue víctima de duras críticas porque por vez primera exponía las lacras de la sociedad a la vista de la gente. Hay un abandono de lo fantástico de antaño para emprender una nueva empresa digna de mayor acogida, ya que cuando el vicio y la miseria se denuncian pueden ser remediados. Otra de las novedades que Muhmūd Taymūr presenta como autor realista es la lengua del diálogo porque es la que verdaderamente está cerca de la realidad, lengua de la que este autor acabará siendo maestro. Defiende en principio la lengua popular ('ammiyya)en el diálogo porque es la que está verdaderamente cerca de la realidad, pero tras varios intentos que demostraron el error en que se hallaba, rectifica en favor de la lengua fusha comprometiéndose sin embargo consigo mismo a hallar un lenguaje fácil, claro y concreto que no entorpezca los diálogos. Este prólogo que hemos comentado es de sumo interés pues es una especie de manifiesto literario al que Mahmūu Taymūr será fiel toda su vida y porque en el 
momento por el que atravesaban las letras árabes tales manifestaciones expresadas con valentía y sinceridad fueron un gran paso en el nuevo camino abierto a la literatura árabe. Detenernos en la temática y carácter de las veintitrés colecciones de cuentos de este autor no es oportuno hacerlo en este momento. Ya existen estudios en todas las lenguas para aquéllos que se quieran asomar a sus páginas. Pero creo oportuno resaltar el estilo y el lenguaje de su obra. En cuanto a la estructura es muy sencilla y lineal. Mahmūd Taymūr abre brecha en este campo imponiéndose la obligación de que sus relatos han de ser el vivo reflejo de la realidad y ello le costó la crítica de sus contemporáneos escandalizados de ver en las páginas de sus cuentos reflejadas todas las lacras de la sociedad y a todos los personajes marginados, máxime cuando él era un aristócrata al margen de estos problemas. Por eso quizás al principio presentó tipos más bien graciosos o simpáticos que produjeran un cierto regocijo, pero la temática va cambiando casi al mismo tiempo que la estructura de su narrativa encontrando un alto grado de perfección en el cuento que él denomina riwāyya qisasiyya, que es $A b \bar{u}$ 'Alì al-fannān (Abū 'Alī el artista) en el que trata un tema de gran actualidad como es el del mundo del teatro. Conforme va pasando el tiempo, el autor madura y sus relatos se hacen más filosóficos, cambiando la técnica del diálogo por la elucubración mental del personaje.

El lenguaje de Mahmūd Taymūr solamente admite el calificativo de bello. Es un lenguaje terso, ligero, armonioso y a la vez muy elaborado a la búsqueda sin desmayo de esa tercera lengua que preconizará Tawfĩq al-Hakīm a la que nuestro autor dará muchas páginas de su producción ensayística. Hay en su lenguaje, sin embargo, calcos extranjeros y gran número de extranjerismos; ambas cosas no son un reflejo inconsciente del medio donde se desarrolla su vida, sino el modo de situar de una forma más perfecta la acción o los personajes.

Si queremos valorar el trabajo de este autor tendremos que decir que indudablemente Mahmūd Taymūr ha de ocupar un lugar importante en la historia de la narrativa breve árabe en general y de la egipcia en particular porque cumple perfectamente su misión en el tiempo. Su habilidad para retratar a los personajes, su maestría en el arte de la narración y la asombrosa jugosidad de su lenguaje le dan derecho a ello.

En cuanto a la influencia que Europa tuvo en este autor, él mismo se declara admirador de Guy de Maupassant tanto por su estilo como por la maestría de sus exposiciones. Considera que dicho autor le influyó sobremanera al igual que Chéjov y Turguenief. A nuestro parecer Mạ̣mūd Taymūr está más próximo de los dos rusos que del francés porque consideramos que su mentalidad coinciden más con aquéllos y porque el medio social en el que unos y otros se desenvuelven tiene más en común: vida urbana, organización del campesinado, repartos de tierras, abismos sociales, etc... ${ }^{7}$

A pesar de su apariencia sosegada y de su dulce modo de expresión, Țāhā Husayn es, sin duda, el personaje más rebelde, más en lucha consigo mismo y

7 E. Gálvez, El Cairo de Mahmūud Taymūr. Tipología literaria (Sevilla; Publicaciones de la Universidad. 1974) p. 39. 
más deseoso de dar a su país un porvenir mejor. No es el momento de entrar en el análisis de esta completa y rica personalidad, pero no podemos olvidar al hablar de él que fue un hombre de letras y un político que luchó por su pueblo y por mejorar su situación como pocos sin que le frenaran las críticas conservadoras ni las intrigas religiosas dando siempre la opinión sincera y expresando sus sentimientos sin paliativos. Se había marcado una meta y la cumplió día a día a lo largo de su vida: poner a prueba la capacidad de la lengua árabe para ver si era capaz de hacer frente a los géneros literarios que los antiguos ho habían abordado ${ }^{8}$. Al-ayyām (Los días), su obra autobiográfica, refleja la lucha para mejorar por medio de la educación el futuro de los jóvenes de su país. Está concebida en tres partes y escrita en tres diferentes períodos de su vida. El primero, publicado en 1929 es un grito literario sobre el estado del campo egipcio con sus enfermedades, su pobreza, estigmas sufridos en su propia carne y de los que fue víctima quedando ciego desde corta edad. Hombre impregnado de la civilización europea y sobre todo de la francesa, lo vemos muy influído por su literatura. Como Corneille introduce en su obra un nuevo tipo de personaje: éste estudia al noble francés; aquél al egipcio del pueblo con una intención común, la de reformar y evolucionar. Pero como todos los autores egipcios de los años veinte está muy influenciado por Guy de Maupassant y de su realismo y, ante el pesimismo sin Dios del francés, Tạhā Husayn presentará otro tipo de pesimismo procedente del hecho de que no encuentra solución a los problemas sociales, pero en su caso con Dios ${ }^{9}$.

Ambos poseen un alma idealista que sufre por los dolores de la humanidad. En Ṭāhā Husayn el concepto de la mujer está dividido entre el amor a su madre, la campesina egipcia y el que profesa a su mujer, Suzanne, la europea que según las propias palabras del autor «le hizo nacer de nuevo». Este amor repartido entre dos extremos tan opuestos bien puede considerarse como un símbolo o una toma de postura ante el dilema en el que se debate la vida del autor. Causa de controversias y desconfianzas por parte del elemento conservador del país, no quiere romper con lo que son sus orígenes, pero sí piensa que además de ésa hay otras verdades, otras realidades enriquecedoras de un espíritu sediento de saber. No reniega de los clásicos y ahí están sus ensayos en ese campo; pero piensa que para los géneros nuevos hay que inclinarse por un tipo de lengua claro y sencillo. Y eso es lo que él consigue, convertirse en un estilista inconmensurable por su dominio del lenguaje dotado de musicalidad y ligereza sin dejar atrás la riqueza de la lengua clásica de la que es acérrimo defensor.

Inquieto, contradictorio, poseedor de una peculiar forma de rebeldía, Tawfiq al-Hakim inicia su obra a principios de los años veinte. A lo largo de su trayectoria literaria se va afirmando más en el teatro dejando a un lado la narrativa, no sin antes legarnos dos espléndidas novelas: Awdat al-rūh (El despertar de un pueblo) (1933) y Yawmiyyāt nā'ib fí-l-aryāf (El diario de un fiscal rural) (1973). Al igual que Maḥmūd Taymūr y que Ṭāhā Husayn, en su incesante trabajo de inves-

8 R. G. Khoury, «Ṭāhā Husayn (1889-1973) et la France». Arabica XXII (1975) 225-240.

9 R. G. khoury, «Tāāā Husayn (1889-1973) et la France» Arabica XXII (1975) 254-266. 
tigación por la evolución del lenguaje, nos dará la clave del mismo con su concepto de tercera lengua que defiende a lo largo de su obra. Valga como muestra de los neologismos por él propuestos el término de masrawiyya con el que define a la novocomedia en traducción de P. Martínez Montávez y que introduce la idea de novela con elementos teatrales incorporados ${ }^{10}$.

Y no hemos tomado este neologismo al azar, sino porque 'Ali B. Jad sugiere que hay algo de técnica teatral en las novelas de Tawfīq al-Hakìm, concretamente en $A$ wdat al-rüh que ofrece por un lado la pintura fiel de costumbres y tipos, por otro el esbozo de una novela autobiográfica que gira en torno a un amor platónico y por último una tesis histórico-política de los viejos valores egipcios que se mantenían inmutables a través de las vicisitudes históricas para reencarnar en el pueblo en el momento necesario y llevarlo nuevamente a la gloria. La novela se inspira en la revolución de $1919^{11}$.

Yawmiyyāt na' 'ib fi-l-aryāf ofrece una temática rural envuelta en la forma de novela policíaca llena de humor y colorido ${ }^{12}$.

No ha faltado entre los mismos egipcios quien haya visto en esta obra un programa de reformas sociales o una especie de crítica en acción de los procedimientos judiciales que regían en Egipto ${ }^{13}$. Es una gran novela en la que el autor escoge una fiscalía rural explicarnos todo el trasfondo de la vida campesina. Un joven licenciado debe dejar El Cairo para trasladarse a un pueblo y desempeñar sus funciones de fiscal. Esta sencilla anécdota que puede parecer a simple vista un hecho sin importancia está planteando una vez más el problema de acomodación entre el pasado y el presente. Que una persona que ha realizado estudios superiores tenga que trasladarse a una aldeíta insignificante es una denuncia paralela, pero en el tono irónico con el que Tawfìq al-Hakìm toca sus temas, a la que Yahyā Haqqī hará de una manera mucho más explícita en su novelita Qindī Umm Hasim, en este caso con la adaptación a su propio medio de un médico egipcio que ha estudiado en Europa.

El lenguaje de Tawfĩq al-Hakīm es una búsqueda incansable de la reconciliación entre lo antiguo y lo moderno haciendo uso de esa tercera lengua que tanto defendió. Para el ya citado 'Ali b. Jad el lenguaje coloquial de los diálogos en ambas novelas se presta por sí mismo a situaciones teatrales. Las sesiones del juez lento y el juez rápido en Yawmiyāt..., por ejemplo hacen trasparentarse al autor de farsas y comedias. También intercala Tawfīq al-Hakīm canciones en sus dos novelas; valgan como muestra las dos siguientes:

«En amor todo son penas; ten cuidado corazón

que la ausencia o el desdén penas de este riesgo son».

10 P. Martínez Montávez, Exploraciones en Literatura neoárabe (Madrid: Instituto HispanoÁrabe de Cultura, 1977) p. 201.

11 Ali ben Jad, Form and Technique in the Egyptian Novel (Oxford, Ithaca Press, 1983) p. 50.

12 T. al-Hakīm, Diario de un fiscal rural, trad. Emilio García Gómez (Madrid: Instituto HispanoÁrabe de Cultura, 1955).

13 T. al-Hakīm, Diario de un fiscal rural, trad. Emilio García Gómez (Madrid: Instituto HispanoÁrabe de Cultura 1955) p. X. 
Canción que recuerda Muhssim evocando a su amada en $A$ wdat al-rūh ${ }^{14}$. O esta otra que repite el sayj loco de Yawmiyyāt $n \bar{a}{ }^{\prime} i b$ fi-l-arya $\bar{a}$ :

«Busca mujeres si quieres

ver la fuente del pesar.

Las pestañas de mi amiga

alfombran medio marjal» ${ }^{15}$.

Naŷib Maḥuz es el último autor al que nos vamos a referir. En él se sintetizan todos los esfuerzos de los maestros anteriores. Empieza escribiendo cuentos en diversos periódicos y revistas y en 1938 publica una colección con el título Hams al-ŷunūn (El murmullo de la locura). Es éste uno de los autores que pronto abandonan el cuento para integrase en la producción del género novelístico. Es imposible pasar por alto ninguna de sus obras, pero los límites del trabajo nos lo imponen por lo que hablaremos de las tres novelas escritas entre 1955 y 1957 que servirán para cerrar el ciclo histórico que nos habíamos propuesto estudiar. Conocidas en su conjunto bajo el nombre de Tulātiyya (Trilogía), el de cada una de ellas por separado, Bayna al-qașrayn (1955), Qasr al-Sawq (1957) y AlSukkariyya (1957) responde a los nombres de tres barrios populares de El Cairo donde se desarrollan los acontecimientos que se narran. La obra es una novela cíclica que abarca a través de tres generaciones la historia de la sociedad egipcia desde 1914 hasta el final de la Segunda Guerra Mundial ${ }^{16}$.

El primer ciclo cuenta la historia de un comerciante, pequeño burgués bien situado que, según las costumbres tradicionales ejerce sobre su mujer y sus hijos una autoridad absoluta. Amina, su esposa, su propiedad privada, cuya vida se limita a los cuatro muros de la casa, es una mujer buena y sencilla, pero ignorante y sometida a la autoridad del marido. La familia tiene cinco hijos, de ellos dos chicas Jadîya la fea que obstaculiza el matrimonio de su hermana Ayša, la guapa. Si la belleza establece fronteras entre ellas, ambas tienen en común la falta de libertad y el sometimiento a la autoridad paterna; el amor está condenado en la familia. La supuesta actitud conservadora del padre no es otra cosa que una fachada tras la cual se oculta un hombre libertino. Y hay tres hijos, Yāsīn, hijo de la primera mujer y que sigue las huellas del padre, Fahmī, el revolucionario y Kamāl, un niño en esta primera parte que se cierra con la muerte de Faḥmī bajo las balas inglesas en la revuelta de 1919 .

Kamāl, el pequeño, abrirá el segundo ciclo. Es un interlectual idealista pero indolente, incapaz de luchar contra sí mismo, será víctima del alcohol y del sexo llevados al paroxismo por su eterna insatisfacción.

14 T. al-Hakīm, El despertar de un pueblo, trad. Federico Corriente (Madrid: Instituto HispanoÁrabe de Cultura, 1967) p. 352.

15 T. al-Hakìm, Diario de un fiscal rural, trad. Emilio García Gómez (Madrid: Instituto HispanoÁrabe de Cultura, 1955) p. 21.

16 A. Chehata, «Les influences étrangères sur la Trilogie de Mahfuz». Arabica XXII (1975) 284-286. 
Los hijos de las dos hermanas protagonizarán el tercer ciclo, aunque, a decir verdad, el protagonista de este último libro es el tiempo ${ }^{17}$.

Si nos preguntamos a grandes rasgos cuáles son las principales características de esta obra diríamos que la originalidad. Todo ocurre a la sombra de la mezquita de Sayyedna el-Husayn. El Cairo se ve dividido a la manera de pequeñas provincias que son sus barrios, quedando a su vez el personaje encerrado en otro círculo que es su propio mundo. Y todos estos círculos convergentes giran en torno a un punto central, la casa, encarnada en la figura de la madre que es, por así decirlo, un personaje estático. Más a su vez ese centro se centrifuga en otros círculos que son las habitación paterna, la cocina, las escaleras, las azoteas, etc.. Pero lejos de servir de pretexto al autor para lanzarse a grandes descripciones, no es así; todo es discreto y austero, todo parece más evocado que descrito ${ }^{18}$. Objetividad sería otra característica digna de tener en cuenta. El personaje no responde al orden de la belleza de las cosas sino a los valores morales. Ese principio del retorno a las fuentes, de la toma de conciencia del autor se va difuminando a lo largo de su obra bajo la forma de provincianismo virtuoso con una convicción profunda, innata y determinante. Y es fuera, en el exterior de El Cairo, donde las acciones vuelven a tomar las medidas de su verdadero destino. Desde ese punto de vista la Trilogía es una obra de arte. Hay en ella un contexto histórico muy importante y en el propio Nayŷîb Mahūz una capacidad de evasión materializada en el desplazamiento hacia nuevas áreas, en busca de algo: las azoteas de Bayna al-qasrayn para atisbar a la amada.

Los personajes en Naŷib Mahūu no dependen del temperamento del autor: no hay narración autobiográfia como en Tawfīq al-Haīm o en Yahyā Haqqi, aunque sepamos que en la Trilogía sentimientos y topografía de los hechos están sacados de los recuerdos de infancia del autor. Son personajes de epopeya en tanto en cuanto representan el sentir del pueblo alargándose este carácter hasta los tipos físicos, la chica guapa, Ayša, la fea, Jadîŷa, el hombre sensual, Yāsīn, etc. La originalidad de estos personajes está en que siendo seres vivos son ejemplares; sus reacciones sicológicas existen -y por tanto la acción novelística- pero son las que se desprenden de la naturaleza de un subgrupo en el que son, cada uno en su esfera propia, los representantes. Comerciantes, funcionarios, prostitutas y sobre todos ellos el estudiante, son importantes por su reparto de papeles en la intriga novelística. En la mayor parte son seres que nunca han perdido y de ahí la exigencia fundamental, la cultura, presente en todas las obras de Naŷîb Maḥfüz. Por las cualidades decisivas de sus personajes la obra es portadora de una lección ${ }^{19}$.

Aunque con una carga mayor de originalidad Naŷīb Maḥfūz sufre también la influencia occidental. Establece sus primeros contactos con las literaturas extranjeras tras sus estudios secundarios. El autor encaminaba entonces sus pasos

17 J. Jomier, «La vie d'une famille au Caire d'après trois romans de M. Naguib Mahfüz » $M I-$ DEO 4 (1957) 27-95.

18 A. Miquel, «La technique du roman chez Neguib Mahfuz» Arabica X (1963) 76-80.

19 A. Miquel, «La technique du roman chez Neguib Nahfuz» Arabica X (1963) 80-84. 
hacia otro campo, el de la filosofía, y dentro de esa orientación estudió el darwinismo y el marxismo. En 1936 da prioridad absoluta a la literatura y se inclina por la novela realista y naturalista, pero indagando en el expresionismo a través de Kafka, en el realismo sicológico con Joyce y en la mutilación del tiempo con Proust. Al contrario que los tres autores anteriores estudiados el vehículo de Naŷib Mahūu es la lengua inglesa y su acceso a la literatura francesa fue a través de aquel idioma y otras veces en traducciones al árabe, pues ya en su época existe el volumen suficiente de obras extranjeras traducidas a este idioma ${ }^{20}$.

Actualmente la producción literaria continúa en Egipto, pero la maestría alcanzada por los autores de los que nos hemos ocupado no ha sido superada, a nuestro parecer, por ningún otro.

NOTA: A punto de concluir la impresión de este trabajo ha visto la luz la versión castellana de Bayna al-Qașrayn (Entre dos palacios), primera parte de la Trilogía de Naguib Mahfuz, realizada por un equipo de traductores del que formo parte.

20 A. Chehata. «Les influences étrangères sur la Trilogie de Maḥfūẓ» Arabica XXII (1975) 282-191. 
